\title{
Protocols on prenatal care for pregnant women with Zika infection and children with microcephaly: nutritional approach
}

Rachel de Sá Barreto Luna Callou Cruz 1

Malaquias Batista Filho 2

Maria de Fátima Costa Caminha 3

Edvaldo da Silva Souza 4

1-4 Instituto de Medicina Integral Prof. Fernando Figueira (IMIP). Rua dos Coelhos, 300. Recife, PE, Brasil. CEP: 50.070-550.

E-mail: rachel.callou@hotmail.com

\begin{abstract}
This summary aimed to synthesize the protocol guidelines of Pernambuco, the Ministry of Health and the Centers for Disease Control and Prevention which deal with health care related to Zika virus infection during pregnancy and the preliminary procedures for surveillance on microcephaly cases including nutritional care. With the increase of number of cases on this event since August, 2015, it was necessary to reorganize the prenatal care which is offered to pregnant women, including the protocols in order to reduce the chances of a possible contamination of the virus, to detect previously suspected cases as well as perform follow up on confirmed cases. The gaps in the knowledge of this morbidity, it should be noted that the information and recommendations are subject to revision due to possible incorporation of new knowledge and other evidence, as well as the need for adequacy of surveillance actions in new epidemiological scenarios. It is known that cases of nutritional deficiencies are capable of producing malformation of the Central Nervous System, including microcephaly. In the analysis of the protocols, there were no changes as to the nutritional recommendations already established for the low-risk pregnant women. The authors presented a hypothesis and conceptually, as a prevention measurement, the inclusion of prenatal care to prevent and control isolated or multiple deficiencies associated to microcephaly, such as protein, vitamin A, iodine, folate, B12, vitamin D, biotin, zinc and selenium.
\end{abstract}

Key words Zika virus, Microcephaly, Gestation, Infection 


\section{Contextualization on Zika virus infection at pregnancy and microcephaly}

Throughout this article it had been sought to summarize the guidelines that address health care related to Zika virus infection at pregnancy and preliminary procedures for surveillance of microcephaly cases, including nutritional care from the protocols of the State of Pernambuco, the Ministry of Health (MS) and the Centers for Disease Control and Prevention (CDC). This initiative arose on observations that there are no records on new nutritional guidelines for pregnant women at risk in developing the virus besides on the nutritional recommendations already established for pregnant women at low risk. Thus, these authors will present throughout the text, a purpose on the inclusion of prenatal care, prevention and control of isolated or multiple deficiencies associated to microcephaly.

In 2015, the surprising growth of microcephaly cases, a disease that is still little known in its natural history, clinical and epidemiological aspects already made countless victims in Brazil, especially in Pernambuco State from a series of cases diagnosed at Instituto de Medicina Integral Prof. Fernando Figueira (IMIP) and notified the Health Department of the State, following by the registration in some other locations in the North and Northeast, leaving the country in a sanitary state of alert.1,2

After several speculations about microcephaly etiology, currently, there is sufficient evidence to infer a causal relation between Zika virus infection in the prenatal period, microcephaly and other severe abnormalities of the brain. The etiological explanation is also supported by the hypothesis absence of plausible alternatives, despite the extensive analysis of possible causes. ${ }^{3}$

Zika virus was initially isolated in Rhesus monkeys in Uganda, Africa in 1947, and it is responsible, until nowadays, for an arbovirus emerging in the world. Until recently, only human cases were sporadically registered. In 2007, the cases related to Zika virus were documented outside the continents of Asia and Africa, with an emphasis on an outbreak in the French Polynesia and subsequently the virus spread to several countries of Oceania. 4

In May 2015, the Pan American Health Organization issued a statement about the transmission risk of the virus in some Northeast cities, which was attributed to the Asian strain of the Zika, confirmed by laboratorial findings. ${ }^{5}$ The autochthonous cases were being dealt in the French Polynesia, thus, probably the tourists brought the virus to Brazil during the International Federation of Football -
World Cup in 2014

Zika virus infection, asymptomatically about $80 \%$ of infected individuals, affects all age groups and both genders characterized by an acute febrile illness and often self limited, which leads to a low need of hospitalization and, as a rule, it has not been associated to complications. ${ }^{1}$ When it is symptomatic, the infection may present low fever (or, possibly, no fever), macula-papular exanthema, arthralgia, myalgia, headache, conjunctival hyperemia and, less frequently, edema, odynophagia, dry cough and gastrointestinal alterations. Severe and atypical forms are rare, but, when they occur, they may exceptionally evolve to death. The signs and symptoms caused by Zika virus, compared to those of other diseases (such as dengue and Chikungunya), including a more enhanced exanthematic framework and conjunctival hyperemia without any significant change in the leukocytes and platelets count. 6

The relation between Zika virus infection and the occurrence of microcephaly disease have gained greater proportions when it started to reach pregnant women, after being confirmed in November, 2015, by the Ministry of Health. The presence of the virus was identified by researchers at Evandro Chagas Institute (IEC) in samples of blood and tissue of a newborn from Ceará who presented to have microcephaly and other congenital malformations. 7 This hypothesis was raised after detecting unexpected increase in the number of microcephaly cases, initially in Pernambuco and subsequently in other States in the Northeast region of Brazil, since October, 2015.8

There has been a substantial increase in the incidence of microcephaly at birth, reaching 1248 cases reported in 2015, in the country. This number is eight times greater than the number of cases in 2010 (153 cases). ${ }^{8}$

In December, 2015, MS published the "Protocol on health care and response to the occurrence of microcephaly related to Zika virus infection", aiming to guide health care professionals through the guidelines to take actions in preventing the infection by the virus in childbearing age women and pregnant women, to draw attention to prenatal care, labor and birth and care for infants with microcephaly, nationwide. 9 The Centers for Disease Control and Prevention (CDC) gathered guidelines to treat pregnant women during the current outbreak of Zika virus $^{10}$ as well as WHO established an alert and considered this morbidity as a worldwide public health. ${ }^{11}$

Microcephaly is an anomaly that the head circumference (PC) is less than minus $2(-2)$ stan- 
dard deviations, in other words, more than 2 standard deviations below the mean for the gestational age and gender.6,11-13 For the newborns (RN's) the term, after successive reviews, it was defined that the cut-off point less than 31.9 centimeters for boys and less than 31.5 for girls. 11 The measurement of the skull should be performed at least 24 hours after the birth and within the first week of life (up to 6 days and 23 hours), by means of technique and standard equipment (e.g. inelastic tape). In addition, the measurement is less than minus three (-3) the standard deviation patterns are defined as severe microcephaly. 14

The occurrence of microcephaly, by itself, does not mean that motor and mental disorders will occur. Children with head circumference below the average may be cognitively normal, especially if it is of family origin. However, most cases of microcephaly are accompanied by abnormalities and cognitive abilities that vary according to the degree of involvement of the brain. In general, children present delayed neuro-psychomotor development with motor involvement and relevant cognitive and in some cases, the sensory functions (hearing and vision) are also at risk. The cognitive deficit occurs in approximately $90 \%$ of the cases. 15,16

It is recommended for previous identification of all pregnant women in the country, by the health care team, until the 12th week of gestation and immediately initiate prenatal care, aiming for opportune interventions in the whole gestational period, whether they are preventive or therapeutic. 17 Before exanthematic disease the procedure should: (a) Shelter the pregnant women; (b) Evaluate the signs and symptoms of the Arboviruses; c) Notify the Sistema de Informação de Agravos de Notificação (SINAN) and Register the events in the Public Health (RESP); d) Initiate the habitual risk prenatal care with complementary examinations; (e) Link to the Maternity, according to Unique Therapeutic Plan for pregnant women. 18

In view of the current state of knowledge on physiopathology infection by Zika virus, there is no reason to change the routine to accompany prenatal care recommended by the Ministry of Health (MS), ${ }^{9}$ and pregnancies not considered by this isolated cause, are not of high risk. However, it is important to ensure the access to specialized references, if it is necessary. In case of primary care, after classifying the risk, identify any changes to indicate the pregnant woman to a network of services to engage in prioritizing her care

The recommendation on obstetric ultrasound should be performed preferably at the first trimester of the pregnancy, this is the time that it is estimated for the gestational age to be more accurate. However, it is necessary that the health care professionals before these women who feel anxious for an assured diagnosis, even during pregnancy, the development or not of the fetus by the viruses, for which certain conducts should be done or perform interventions such as ultrasound examinations in series to identify microcephaly, which does not change the condition or prognosis in these cases. ${ }^{9}$

It is the responsibility for the managers and the Family Health Teams: to ensure human, material and technical resources that are necessary for the prenatal care; ensure the initiation of prenatal care in a timely manner and consults as a recommended routine by MS (monthly until the 28th week, biweekly between the 28th and the 36th week and weekly from the 36 th week and until the baby's birth); to promote active listening for the pregnant woman and the companion(s), considering intellectual, emotional, social and cultural aspects and not only a biological care. 9

There should also perform an active search of pregnant women who missed the appointments, so that they have the adequate prenatal care; guide the population about prevention and control actions, such as avoiding hours and places where the presence of mosquitoes are; use continuously clothes that protect the exposed parts of the body, such as arms and legs; alert the pregnant woman and companion on vector control (eliminating at home possible breeding places for the mosquitoes, cleaning the land, disposal of garbage and materials and adequate use of the water) and encourage the use of screens, mosquito nets or other available barriers. 9

Health professionals should provide guidance on the use of repellents and its frequent use for pregnant women. It is recommended to use only products duly regulated at the National Health Surveillance Agency (ANVISA). 19 Studies point out that the topical use of repellents based on n,n-Diethyl-metatoluamide (DEET) by pregnant women is safer.20,21 The "natural" repellents based on citronella, andiroba, clove oil and among others, have no proof of efficacy nor the approval by ANVISA until this moment. Besides the recommendations already established for low risk prenatal, 17 should be investigated and register in the pregnant women's medical book or card, as well as in the women's medical files, the occurrence of infections, cutaneous rash, exanthema, or fever, directing the woman to seek the health service in the occurrence of these signs and symptoms. At all times of the prenatal care there 
should be attentive to the clinical signs and symptoms of Zika virus infection. ${ }^{9}$

It is important to clarify that the evidence of an exanthematic infection during pregnancy, does not necessarily lead to the occurrence of microcephaly in the fetus. In case the pregnant woman has acute exanthematic disease (five days of exanthema), and other possibilities of infectious diseases and noninfectious causes are excluded, then the material should be collected for examination.9-11

The testing for Zika virus is among the measurements indicated by the Ministry of Health in the protocol that defines the preliminary procedures to be adopted for the surveillance of microcephaly cases in Brazil. For women with macula popular exanthema must collect 5 to $10 \mathrm{~mL}$ of peripheral blood during the acute phase of the disease - until the 5 th day after the onset of the first symptoms, for virological testing to establish differential diagnosis for Zika virus, chikungunya, dengue, cytomegalovirus, rubella, toxoplasmosis and B19 parvovirus. It is also recommended to perform laboratorial test for polymerase chain reaction (PCR) for Zika virus, chikungunya, dengue, cytomegalovirus and toxoplasmosis in peripheral blood and in the urine. 9,22

Suspected cases must be notified, according to the "Protocol for Surveillance and Response in the occurrence of microcephaly related to Zika virus infection"9 guidelines in the National System for Notable Diseases and registration of microcephaly cases in the Public Health Registration Events. 23 It is fundamental to notify, to activate the investigation process, aiming to confirm the cases, as well as subsidize the health care actions. In case of conclusive laboratorial diagnosis for Zika virus is defined as "confirmed case" for pregnant women under the risk of the fetus with microcephaly is a possible exposure to Zika virus.

Ideally, at least two to three ultrasounds should be performed during the pregnancy for women with an exanthema history: one in the first quarter to correct date of pregnancy, a second with 20-22 weeks to check the fetal morphology and another in the third quarter.22,24 This latter is to evaluate fetal development, the amount of amniotic fluid and also to detect changes in the fetal morphology as the case of microcephaly that may occur later on. ${ }^{24}$

In case the pregnant women's obstetric ultrasound show a fetus with a cranial circumference (CC) measuring less than two standard deviations $(<2 \mathrm{dp})$ below the average for gestational age, or with changes in the Central Nervous System (SNC) suggestive of congenital infection, this can be considered as a "suspected case" for microcephaly related to Zika virus at pregnancy. ${ }^{24}$

The confirmation of microcephaly related to Zika virus during pregnancy occurs by the following criteria 9 :

1- Confirmed case of fetus with post-infectious alterations in the $\mathrm{SNC}$ related to Zika virus: a fetus with alterations in the SNC with characteristics of congenital infection identified by the ultrasound and report of exanthema on the mother during pregnancy, other possible causes, infectious and non-infectious diseases, should be excluded.

2- Confirmed case of fetus with microcephaly postinfectious disease related to Zika virus: a fetus with microcephaly identified by ultrasound, showing alterations in the SNC with characteristics of congenital infection and report of exanthema on the mother during pregnancy, infectious and non-infectious diseases, when excluding other possible causes. 3- Confirmed case of miscarriage related to Zika virus: spontaneous abortion in pregnant woman with reports of exanthema during pregnancy, without other proven causes, identification of Zika virus in the fetal tissue/embryo or in the mother.

The health team should be sensitized to shelter pregnant woman with suspected case and her anxieties, doubts and fears, by means of a qualified listening, without judging or prejudice, allowing the woman to speak about her intimacy with security.

When necessary, the Family Health Teams may request the matrix support of mental health professionals by the Family Health Support Nucleus (NASF) or from other mental health professionals from the city. 14

The evidence of the fetus with post-infectious microcephaly related to the viruses does not determine the indication of alternating the obstetric delivery route, in other words, Zika virus infection or microcephaly itself are not an indication of cesarean surgery. It is important to highlight that unnecessary cesarean section increases the risk of complications for both the mother and the newborn. 14

It is important to observe that none of the protocols of the Secretary of Health of Pernambuco,22 The Ministry of Health and the $\mathrm{CDC}^{10}$ mentioned the likely role of the nutrition state, when various nutritional deficiencies can produce congenital malformations, including microcephaly and even anencephaly. Maintaining the previous recommendations for monitoring low risk prenatal care, ten steps for a healthy diet for pregnant women, including dietary guidance, food groups and the necessary daily servings. a) supplementation of folate, take routinely for at least two months before and during the first 


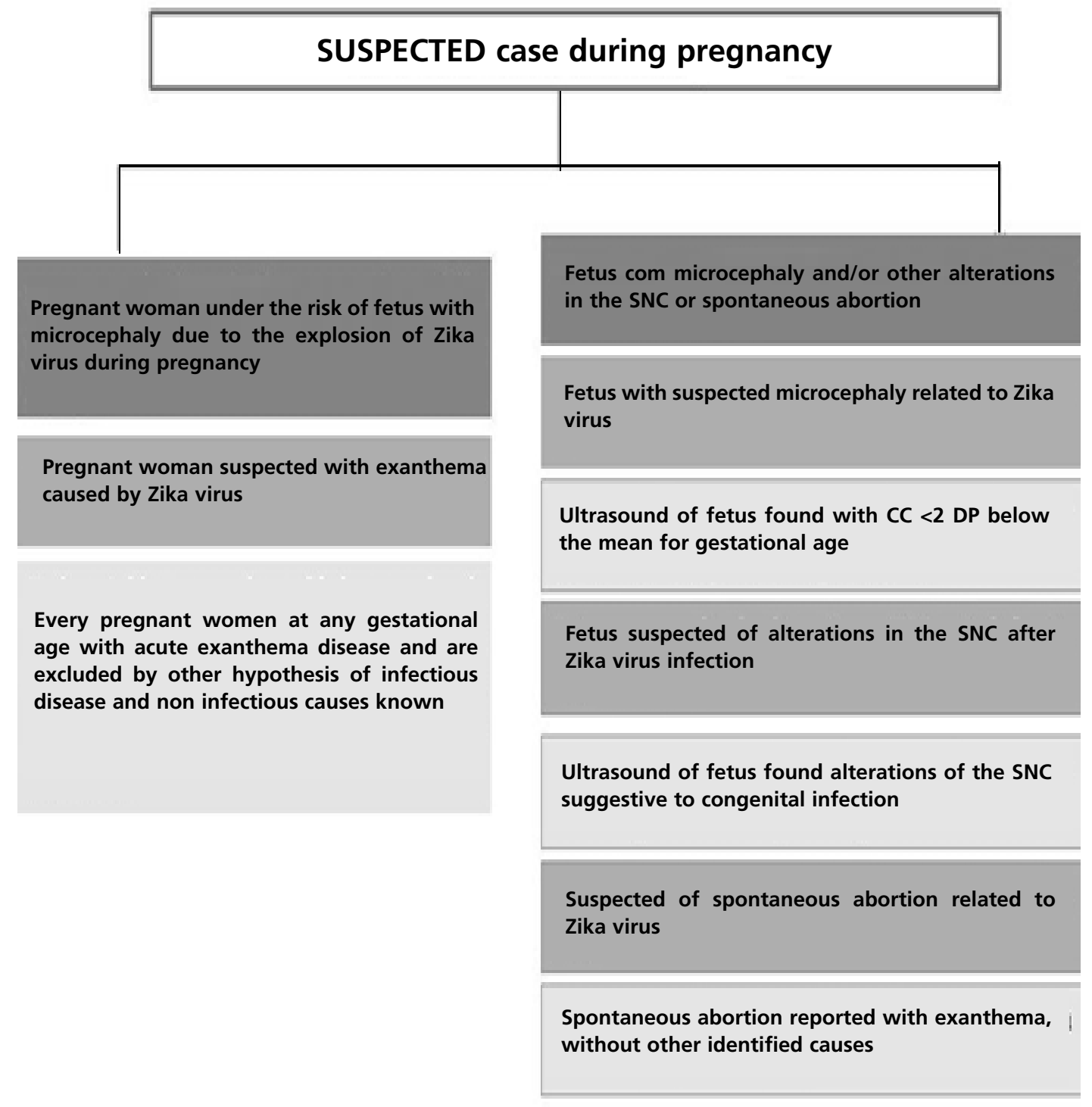

Source: Protocol for health care and response to the occurrence of microcephaly related to infection by Zika virus, 2015.24 
two months of pregnancy, as a form of protection against open defects of the neural tube; b) Iron supplement at 20th week to prevent anemia (hemoglobin $>11 \mathrm{~g} / \mathrm{dL}$ ) take a pill of ferrous sulphate a day (200mg), which corresponds to $40 \mathrm{mg}$ of elemental iron. If light to mild anemia is observed (Hemoglobin between $8 \mathrm{~g} / \mathrm{dL}$ and $11 \mathrm{~g} / \mathrm{dL}$ ) a treatment with 120 to $240 \mathrm{mg}$ of elemental iron is recommended per day, equivalent to five pills a day. And in severe anemia (Hemoglobin $<8 \mathrm{~g} / \mathrm{dL}$ ) will be necessary to refer the pregnant woman to high risk prenatal care. 17

The supplementation of pyridoxine (vitamin B6), calcium, zinc and protein for pregnant women at low risk are not yet recommended by the Ministry of Health. In relation to vitamin A, it is recommended just for puerperal living in the Northeast region and in the cities of Minas Gerais State (in the North of the State and in the valleys of Jequitinhonha and Mucuri), and even in immediate post-partum period, at the maternity. They should receive a mega dose of 200.000 IU of vitamin A (1 capsule orally), to ensure adequate levels of retinol in the breast milk until the baby reaches 6 months of age, thus decreasing the risk of deficiency of this vitamin among breastfed children. The benefit of its use in the prenatal is still not defined. 17

In view of many gaps that still exist in the knowledge about Zika virus infection, its pathogenicity, the clinical characteristics and the potential complications arising from the infection caused by this agent, it should be emphasized that the information and recommendations made by MS are subject for review and changes of any eventual acquisitions of new knowledge and other evidence, as well as the need for adequacy of surveillance actions in future epidemiological scenarios. According to MS, the researches on microcephaly and its relation to Zika viruses should continue to clarify issues such as the transmission of this agent and its activity in the human body, especially in pregnant women and their newborns. Besides the possibility of possible participation of other environmental agents such as nutritional aspects at pregnancy, exposure to drugs (e.g. alcohol) and pesticides.

Most recently, in July, 2016, during a meeting in Pernambuco, the Pan American Health Organization and the World Health Organization (PAHO/WHO) updated the preliminary characterization of the Congenital Syndrome of Zika, which in addition to the signs known formerly as microcephaly, encompass clinical conditions and findings of neuroimaging, mainly related to the central nervous system, such as epilepsy, hearing and visual impair- ments and psychomotor development, as well as the effects on bones and joints.

\section{A nutritional hypothesis}

Of course without integrating the already extensive set of protocols issued by MS, other institutions and researchers, the authors of this article consider relevant and timely to summarize the reason to study the participation of nutritional factors in the etiopathogenesis microcephaly of cases which now manifests itself with a tendency to epidemic outbreaks. Specifies a set of factors and arguments that could support this hypothesis:

a) Historically, biblical documents already recognized the secular trend to associate between the so-called plague diseases (cholera, bubonic plague, scarlet fever, smallpox, typhus and others), hunger (it is understood as old manifestations of deficiencies diseases) and wars, as a geopolitical event. It was the trilogy of plague/hunger/war, producing devastating cycles of diseases and deaths. 25

b) More than 60 years ago, a committee of experts mobilized by WHO15 developed an extensive and detailed report by systematizing the interactions among infections, parasitic infections and diseases deficiencies, summarizing its conclusions in recognition that nutritional deficiencies are the main predisposing factor or aggravating factor of infections which, in turn, act as the triggering agent of clinical forms and serious deficiency cases, such as the Kwashiokor, vitamin A deficiency, anemia, pellagra, beriberi and others. The theme was revisited in 1997, focusing on, in particular, the immunological mechanisms of such interactions. 26

c) A more specific approach, many situations of nutritional deficiencies are capable of producing poor formation of SNC, including changes in the cerebral cortex, spinal bifida, microcephaly, and even instances of anencephaly and anophthalmia. 27 There would be cases extensively documented in experimental level and clinical, according to the severe energetic protein malnutrition, iodine, folate, B12, vitamin D, biotin, zinc, selenium deficiencies and other nutrients. These deficiency problems are found frequently in our pregnant women, with prevalence ranging from $5 \%$ to $40 \%$. This commonly happens in other poor countries. 28

d) On the other hand, several infectious diseases such as toxoplasmosis, rubella, cytomegalovirus, syphilis, herpes, HIV and other are capable, by themselves, to produce microcephaly cases and/or impairment of the central nervous system. The greatest central risk of damage and the peripheral 
nervous system in relation to these diseases are manifested in the first quarter including the prepregnancy, both for infections and nutritional deficiencies.

e) And here is the hypothesis itself. If several deficiency problems may result in morphofunctional changes in the central nervous system, including microcephaly, and if several infectious processes also are known to be related to the pathogenesis of this condition, it is permissible to hypothesized with reasonable consistency of arguments, that the simultaneous occurrence in two situations could interact by adding and multiplying its potential risks, coming as well to increase the chance of the appearance of microcephaly. The argument would be strengthened by two additional reasons, one of which it is remembered: the greater vulnerability of the brain in life of an embryo/fetal focuses until 3-4 months after conception, the same happened in relation to infectious problems already well known.15.16 The second argument would be considered the electivity neutropic of Zika virus, often identified in neural tissue and cerebrospinal fluid. And, possibly, with a capacity to cause damage to the central nervous system is equivalent or perhaps greater than other infectious processes already studied.

The hypothesis of interaction 'maternal nutri-

\section{References}

1. Zanluca C, Melo VCA, Mosimann ALP, Santos GIV, Santos CND, Luz K. First report of autochthonous transmission of Zika virus in Brazil. Mem Inst Oswaldo Cruz. 2015; 110 (4): 569-72.

2. Campos GS, Bandeira AC, Sardi SI. Zika Virus outbreak, Bahia, Brazil. Emerg Infect. 2015; 21 (10): 1885-6.

3. Rasmussen SA, Jamieson DJ, Honein MA, Petersen LR. Zika Virus and Birth Defects - Reviewing the Evidence for Causality. N Engl J Med. 2016; 374 (20): 1982-7.

4. Faye O, Dupressoir A, Weidmann M, Ndiaye M, Alpha Sall A. One-step RT-PCR for detection of Zika virus. J Clin Virology. 2008; 43 (1): 96-101

5. Luz KG, Santos GIV, Vieira RM. Febre pelo vírus Zika. Epidemiol Serv Saúde. 2015; 24 (4): 785-8.

6. Brasil. Ministério da Saúde. Secretaria de Atenção à Saúde. Protocolo de atenção à saúde e resposta à ocorrência de microcefalia [recurso eletrônico] / Ministério da Saúde, Secretaria de Atenção à Saúde. - Brasília, DF; 2016. 42 p.

7. Brasil. Ministério da Saúde (BR). Ministério da Saúde confirma relação entre vírus Zika e microcefalia [Internet]. Brasília: Ministério da Saúde; 2015. [acesso em 1 abril 2015]. Disponível em: http://portalsaude.saude.gov.br/ index.php/cidadao/principal/agencia-saude/21014-ministerio-da-saudeconfirma-relacao-entre-virus-zika-e-microcefalia tional deficiency/Zika virus disease', as a possible combination of risk factors in the microcephaly genesis, even though it will not be safely proven, it would have an important beneficial side effect in valuing the diagnostic conducts, preventive actions and therapeutic measurements for deficiency problems quite frequent since the preconception to pregnancy, especially in the first trimester of pregnancy, when the nutritional condition is clearly neglected, as it always happens in Brazil. In other words, researching for evidence, the relation to single or multiple nutritional deficiency can affect $40 \%$ or more of our pregnancies, it could ultimately contribute to a more effective care for this issue and its various adverse effects on the mother and child during pregnancy.

From this perspective, in addition to characterize situations of deficiencies in which could by etiopathogenic interaction, relating to, hypothetically, the Congenital Zika Syndrome, proposes to incorporate these deficiencies in the routine of treatments on diagnosed cases. It would be a preliminary experiment to justify new care with nutritional condition of the pregnant women, in addition to the measurements that are practiced in the usual routine of prenatal care.

8. Brasil. Ministério da Saúde. Secretaria de Vigilância em Saúde. Situação epidemiológica de ocorrência de microcefalias no Brasil, 2015. Bol Epidemiol. 2015; 46 (34): 1-3.

9. Brasil. Ministério da Saúde. Protocolo de atenção à gestante com suspeita de Zica e à criança com microcefalia. Brasília, DF; 2016.

10. CDC (Centers for Diseases Control and Prevention). CDC Issues Guidelines for Zika Virus in Pregnancy CME/CE. [acesso em 20 de abril 2016]. Disponível em: http://www.sbp.com.br/src/uploads/2016/02/CDC-IssuesGuidelines-for-Zika-Virus-in-Pregnancy_Medscap.pdf

11. WHO (World Health Organization). Assessment of infants with microcephaly in the context of Zika virus - Interim Guidance - 4 March 2016 [Internet]. Genebra; 2016. [Acesso em: 12 de maio 2016]. Disponível em: http://apps.who.int/iris/bitstream/10665/204475/1/WHO_Z IKV_MOC_16.3_eng.pdf?ua $=1$

12. Duncan BB, Schmidt MI, Giugliani ERJ, Duncan MS, Giugliani C. Medicina Ambulatorial - 4.ed.: Condutas de Atenção Primária Baseadas em Evidências [Internet]. 2014. [Acesso em: 06 de maio 2016]. Disponível em: https://books.google.com/books?hl=pt-BR\&lr=\&id= 4HZQBAAAQBAJ\&pgis=1 
13. Harris SR. Measuring head circumference: Update on infant microcephaly. Can Fam Physician. 2015; 61 (8): 6804.

14. Brasil. Ministério da Saúde. Secretaria de Vigilância em Saúde. Departamento de Vigilância Epidemiológica. Nota informativa $\mathrm{n}^{\circ} 1$, de 17 de novembro de 2015. Procedimentos preliminares a serem adotados para a vigilância dos casos de microcefalia no Brasil [Internet]. Brasília, DF; 2015.

15. Scrimshaw N, Taylor C, Gordon J. Interactions of nutrition and infection. Geneva: Word Health organization Monograph Series No $57 ; 1968$

16. Ashwal S, Michelson D, Plawner L, Dobyns WB. Practice parameter: Evaluation of the child with microcephaly (an evidence-based review): report of the Quality Standards Subcommittee of the American Academy of Neurology and the Practice Committee of the Child Neurology Society. Neurology. 2009; 73 (11): 887-97.

17. Brasil. Ministério da Saúde. Atenção ao Pré-natal de Baixo Risco. Série A. Normas e Manuais Técnicos. Cadernos de Atenção Básica, n. 32. Brasília, DF; 2012.

18. Brasil. Ministério da Saúde. Secretaria de Atenção à Saúde Gravidez, parto e nascimento com saúde, qualidade de vida e bem-estar / Ministério da Saúde, Secretaria de Atenção à Saúde, Departamento de Ações Programáticas Estratégicas, Área Técnica de Saúde da Criança e Aleitamento Materno. Área Técnica de Saúde da Mulher. - Brasília, DF; 2013.

19. Brasil. Ministério da Saúde. Agência Nacional de Vigilância Sanitária (Anvisa). Resolução RDC n. 19, de 10 de abril de 2013. Dispõe sobre os requisitos técnicos para a concessão de registro de produtos cosméticos repelentes de insetos e dá outras providências. Diário Oficial [DOU] República Federativa do Brasil. Poder Executivo, Brasília, DF; 11 abr. 2013. Seção 1 .

20. McGready R, Hamilton KA, Simpson JA, Cho T, Luxemburger C, Edwards R, Looareesuwan S, White NJ, Nosten F, Lindsay SW. Safety of the insect repellent n, ndiethyl-m-toluamide (deet) in pregnancy. Am J Trop Med Hyg. 2001; 65 (4): 285-9.

Received on June 21, 2016

Final version presented on September 5, 2016

Approved on September 6, 2016
21. Koren G, Matsui D, Bailey B. DEET-based insect repellents: safety implications for children and pregnant and lactating women. CMAJ. 2003; 169 (3): 209-12.

22. Pernambuco. Secretaria Estadual de Saúde de Pernambuco. Secretaria Executiva de Vigilância em Saúde. Protocolo Clínico e Epidemiológico para investigação de casos de microcefalia no estado de Pernambuco. Versão $\mathrm{N}^{\circ} 02$. Pernambuco: Secretaria Estadual de Saúde; 2015. 42p.

23. Registro de Eventos em Saúde Pública: Registro de casos de Microcefalia e/ou alteração do sistema nervoso central (SNC). [acesso em 4 maio 2016]. Disponível em: http://www.resp.saude.gov.br/microcefalia\#/painel

24. Brasil. Ministério da Saúde. Secretaria de Atenção à Saúde. Protocolo de atenção à saúde e resposta à ocorrência de microcefalia relacionada à infecção pelo vírus Zika. Brasília, DF; 2015.

25. Castro J. Geografia da fome: a fome no Brasil. 1 ed. Rio de Janeiro: O Cruzeiro, 1946

26. Scrimshaw NS, SanGiovanni JP. Synergism of Nutrition, Infection, and Immunity: An Overview. Ann J Clin Nutr. 1997; 66 (2): 464S-477S.

27. Pelizzo G, Calcaterra V, Fusillo M, Nakib G, Ierullo AM, Alfei A, Spinillo A, Stronati M, Cena H. Malnutrition in pregnancy following bariatric surgery: three clinical cases of fetal neural defects. Nutr J. 2014; 13 (59): 2-6.

28. Jiang T, Christian P, Khatry SK, Wu L, West PJ. Micronutrient deficiencies en early pregnancy are common, concurrent and vary by season among rural Nepali pregnant women. J Nutr. 2005; 135 (1): 1106-12. 